\begin{tabular}{c} 
PEDIOMATERNAL \\
NURSING JOURNAL \\
Vol. 5, No. 1, Maret 2019 \\
Jediomaternal \\
Journal Homepage: https://e-journal.unair.ac.id/PMNJ// \\
\hline
\end{tabular}

Original Research

\title{
Faktor yang berhubungan dengan Praktik Vaginal douching pada Wanita Usia Subur dengan Pendekatan Teori Health Belief Model
}

\section{(Factors related to Vaginal douching Practices in Child-Bearing Age Women with the Theory of Health Belief Model Approach)}

\section{Gaharuni Sahika Mutdinia, Retnayu Pradanie, dan Tiyas Kusumaningrum}

Fakultas Keperawatan, Universitas Airlangga, Surabaya, Jawa Timur, Indonesia

\author{
ARTICLE HISTORY \\ Received: March 17, 2019 \\ Accepted: April 30, 2019

\section{KEYWORDS} \\ vaginal douching; health belief \\ model; women child-bearing \\ age
}

\section{CORRESPONDING AUTHOR}

Gaharuni Sahika Mutdinia gaharuni.sahika.mutdinia 2017@fkp.unair.ac.id Fakultas Keperawatan, Universitas Airlangga, Surabaya, Jawa Timur, Indonesia

Cite this as:

\begin{abstract}
Introduction: The practice of vaginal douching is still widely practiced by women of childbearing age without an indication of health. The aim of this research is to know the relationship between factors of vaginal douching practice based on the Health Belief Model Theory among women of child-bearing age.

Methods: This research was conducted by using descriptive analytic design with cross sectional approach. Population of this research are women child-bearing age in Gelangan Village. Sample on this research was 169 respondents which were chosen by using cluster sampling technique. Independent variables in this research were perceived of seriousness, perceived of suscepbility, perceived of benefits, perceived of barriers, cues to action and self-efficacy. Dependent variable in this research was vaginal douching practice. The data colleting technique used in this research was questionnaire which was analysed by using Regresi Logistic test with $\alpha \leq 0,05$ level significance.

Results: The result showed that perceived benefits $(\mathrm{p}=0.008)$ and perceived barriers $(p=0.001)$ were correlated with vaginal douching practice. However, perceived seriousness $(p=0.809)$, perceived suscepbility $(p=0.272)$, cues to action $(0.420)$ and selfefficacy $(\mathrm{p}=0.228)$ were not correlated with vaginal douching practice among women child-bearing age.

Conclusion: Perceived of high benefits and perceived of low barriers was increased vaginal douching practice among women child-bearing age. However, other components of HBM theory such as perceived seriousness, perceived suscepbility, cues to action and self-efficacy were not related to vaginal douching practice. The next research were expected to explore related modifying factors.
\end{abstract}

Mutdinia, G. S., Pradanie, R., \& Kusumaningrum, T. (2019). Faktor yang berhubungan dengan Praktik Vaginal douching pada Wanita Usia Subur dengan Pendekatan Teori Health Belief Model. Pediomaternal Nurs. J., 5(1), 69-76.

\section{PENDAHULUAN}

Wanita memiliki masalah pada area vagina seperti infeksi vagina yang disebabkan oleh hubungan seks, minum antibiotika dalam waktu yang lama, penggunaan sabun dengan $\mathrm{pH}$ yang tidak sesuai sehingga menimbulkan keputihan (1). Salah satu upaya untuk mencegah keputihan adalah melakukan perawatan wanita yang disebut bilas vagina (1).

American College of Obstetricians and Gynecologist (ACOG) menyarankan wanita sebaiknya menghindari melakukan douching(2). Penelitian (3) mengatakan bahwa 2 produk cairan bilas vagina terbukti menghambat pertumbuhan flora baik pada vagina sehingga akan menganggu fungsi normal vagina (3). Studi pendahuluan di kelurahan Gelangan, kota Magelang menunjukkan 18 wanita usia subur (100\%) mengatakan bahwa bilas vagina sangat penting dilakukan agar terhindar dari bakteri serta tejaga kebersihannya. Sebanyak 17 orang (94,4\%) dari 18 wanita melakukan bilas vagina menggunakan air biasa dengan air rebusan daun sirih (50\%), air biasa (22\%), sabun mandi (11\%), cairan pembersih vagina (11\%) dan ada yang menggunakan ke empat bahan 
tersebut (6\%). Praktik tersebut dilakukan setelah melakukan hubungan intim (29\%), mengurangi bau vagina dan membuat kesat (39\%), membilas darah haid setelah selesai mentruasi (10\%) dan mengurangi keputihan (22\%). Bilas vagina (vaginal douching) dikaitkan dengan masalah kesehatan pada wanita karena bilas vagina merusak flora normal dalam vagina sehingga memberikan risiko tumbuhnya bakteri vaginosis (BV) (4).

Ketidakseimbangan pH vagina mengakibatkan tumbuhnya jamur dan kuman-kuman yang lain. Adanya flora normal dibutuhkan untuk menekan tumbuhan yang lain itu untuk tidak tumbuh subur. Jika keasaman dalam vagina berubah maka kumankuman lain dengan mudah akan tumbuh sehingga akibatnya bisa terjadi infeksi yang akhirnya menyebabkan keputihan, yang berbau, gatal, dan menimbulkan ketidaknyamanan (5). Terdapat beberapa faktor yang dapat mempengaruhi seseorang melakuan tindakan vaginal douching. Ditinjau dari teori Health Belief Model (HBM), perilaku individu dalam memutuskan tindakan kesehatan dipengaruhi oleh pandangan/ persepsi dirinya terhadap perilaku tersebut tanpa memperdulikan pandangan tersebut sesuai atau tidak dengan kenyataan.

Teori HBM menggambarkan tindakan pencegahan dipengaruhi oleh dua penilaian yaitu ancaman yang dirasakan individu dari penyakit yang dirasakan berupa persepsi kerentanan serta persepsi keseriusan dan pertimbangan keuntungan serta kerugian untuk melakukan tindakan pencegahan terebut.Terdapat 6 elemen yang mendasari hal ini dalam teori HBM yaitu persepsi kerentanan (perceived suscepbility), persepsi keseriusan (perceived seriousness), persepsi manfaat (perceived benefits), persepsi hambatan (perceived barriers), pendorong tindakan (cues to action), dan efikasi diri (self-efficacy).

\section{METODE}

\subsection{Desain}

Penelitian ini adalah studi kuantitatif dengan jenis penelitian deskriptif-analitik dengan pendekatan cross sectional karena pengukuran variabel independen dan variabel dependen dilakukan hanya satu kali pada satu waktu.

\subsection{Populasi, sampel, dan sampling}

Populasi dalam penelitian adalah wanita usia subur di kelurahan Gelangan, kota Magelang yang berjumlah 292 orang. Tehnik sampel dilakukan dengan tehnik cluster sampling dan didapatkan sebanyak 169 responden dengan pembagian dari RW 2 sebanyak 36 wanita usia subur, RW 6 sebanyak 46 wanita usia subur, RW 10 sebanyak 46 wanita usia subur dan RW 8 sebanyak sebanyak 44 wanita usia subur.

\subsection{Variabel}

Variabel independen dalam penelitian ini adalah persepsi keseriusan, persepsi kerentanan, persepsi manfaat, persepsi hambatan, pendorong tindakan dan efikasi diri. Variabel dependen pada penelitian ini adalah praktik vaginal douching.

\subsection{Instrumen}

Instrumen yang digunakan adalah yang di modifikasi dari penelitian (6) tentang praktik vaginal douching yang dinyatakan valid dan reliable Skoring yang diberikan dalam kuisioner ini ada 2 yaitu penilaian favourable sangat setuju bernilai 4, setuju bernilai 3, tidak setuju bernilai 2 , sangat tidak setuju bernilai 1 dan penilaian unfavourable sangat setuju bernilai 1 , setuju bernilai 2 , tidak setuju bernilai 3 , sangat tidak setuju bernilai 4 kemudian dikategorikan dengan rumus $\mathrm{T}$ mean, apabila $\mathrm{T}>$ mean maka diinterpretasikan tinggi dan $\mathrm{T}<$ mean diintrepetasikan rendah

\subsection{Prosedur}

Sebelum penelitian dimulai, peneliti mengurus surat permohonan izin pengambilan data awal dari Fakultas Keperawatan Universitas Airlangga ditujukkan kepada Kesbangpol Provinsi Jawa Timur diteruskan ke Dinas Penaman Modal dan Pelayanan Terpadu Satu Pintu Provinsi Jawa Tengah untuk mendapat surat rekomendasi penelitian yang di lampirkan bersama dengan surat pengantar ke Kesbangpol Kota Magelang pada tanggal 20 Oktober 2018. Setelah mendapatkan surat rekomendasi dari DPMPTSP Jawa Tengah, penelti memasukan surat tersebut bersama dengan surat pengambilan data awal dan mendapat balasan pada tanggal 29 Oktober 2018. Selanjutnya pengambilan data awal, data yang diambil adalah data jumlah wanita usia subur di Kecamatan Magelang Tengah. Setelah itu dilakukan penyusunan proposal dan ujian proposal yang dilanjutkan dengan Uji Etik. Seminar proposal dilakukan pada tanggal 5 November 2018. Sertifikat uji etik keluar pada tanggal 12 Desember 2018.

Langkah selanjutnya adalah permohonan perizinan penelitian dari akademik Fakultas Keperawatan Universitas Airlangga ditujukkan kepada Bakesbangpol Kota Magelang. Setelah mendapat izin dari Bakesbangpol Kota Magelang, peneliti yang kemudian menuju ke Kelurahan yang berada di Kecamatan Magelang Tengah untuk menemui masing-masing ketua RW dan RT untuk melakukan penelitian pada tanggal 17 Desember 2018-7 Januari 2019. Setelah mendapatkan ijin dari RW dan RT setempat, kegiatan pengambilan data responden, sebelumnya peneliti mengajukan inform concent kepada responden. Setelah meminta persetujuan untuk menjadi responden penelitian (informed consent). Langkah berikutnya adalah pelaksanaan pengisian kuesioner, peneliti mendampingi responden selama pengisian kuesioner untuk membantu responden bila mengalami kesulitan dalam pengisian kuesioner.

\subsection{Analisis}

Penelitian ini menggunakan uji analisis Regresi Logistik dengan $p$ value $<0,05$. 


\subsection{Ethical Clearance}

Penelitian ini telah dinyatakan lolos uji etik dan mendapatkan sertifikat Ethical Approval dengan nomor 1201-KEPK yang dikeluarkan oleh Komisi Etik Penelitian Kesehatan Fakultas Keperawatan Universitas Airlangga pada tanggal 12 Desember 2018.
Sebanyak 57 orang $(33,7 \%)$ memiliki tingkat persepsi keseriusan rendah dan sebanyak 112 orang (66,3\%) memiliki tingkat persepsi keseriusan tinggi dimana subyek penelitian yakin bahwa praktik vaginal douching penting untuk dilakukan guna menjaga kesehatan organ kewanitaan. Sebanyak 97 orang $(57,4 \%)$ memiliki tingkat persepsi kerentanan

Tabel 1. Karakteristik responden di Kelurahan Gelangan Desember 2018

\begin{tabular}{|c|c|c|c|}
\hline Data Demografi & Karakteristik & Frekuensi & Persentase (\%) \\
\hline \multirow{4}{*}{ Umur } & 20-30 Tahun & 54 & 32 \\
\hline & 31-40 Tahun & 73 & 43,2 \\
\hline & 41-49 Tahun & 42 & 24,9 \\
\hline & Total & 169 & 100 \\
\hline \multirow{5}{*}{ Pendidikan Terakhir } & $\mathrm{SD}$ & 3 & 1,8 \\
\hline & SMP & 19 & 11,2 \\
\hline & SMA/SMK/MA & 78 & 46,2 \\
\hline & Perguruan Tinggi & 69 & 40,8 \\
\hline & Total & 169 & 100 \\
\hline \multirow{5}{*}{ Pekerjaan } & PNS & 20 & 11,8 \\
\hline & Pegawai Swasta & 59 & 34,9 \\
\hline & Wiraswasta & 6 & 3,6 \\
\hline & Ibu Rumah Tangga & 84 & 49,7 \\
\hline & Total & 169 & 100 \\
\hline \multirow{3}{*}{ Keputihan } & Tidak & 103 & 60,9 \\
\hline & $\mathrm{Ya}$ & 66 & 39,1 \\
\hline & Total & 169 & $100^{\prime}$ \\
\hline \multirow{3}{*}{ Praktik Vaginal Douching } & Tidak & 49 & 29 \\
\hline & $\mathrm{Ya}$ & 120 & 71 \\
\hline & Total & 169 & 100 \\
\hline \multirow{5}{*}{ Frekuensi } & Sering & 65 & 38,5 \\
\hline & Cukup Sering & 35 & 20,7 \\
\hline & Jarang & 20 & 11,8 \\
\hline & Tidak pernah & 49 & 29 \\
\hline & Total & 169 & 100 \\
\hline \multirow{8}{*}{ Bahan } & Air biasa & 5 & 3 \\
\hline & Sabun Mandi & 39 & 23,1 \\
\hline & Rebusan Daun Sirih & 34 & 20,1 \\
\hline & Betadin & 8 & 4,7 \\
\hline & Cairan pembersih Vagina & 33 & 19,5 \\
\hline & Lainnya & 1 & 0,6 \\
\hline & Tidak Menggunakan & 49 & 29 \\
\hline & Total & 169 & 100 \\
\hline
\end{tabular}

\section{Hasil}

Karakteristik responden menunjukkan dari segi umur dengan persentase terbanyak ada usia 31-40 tahun yaitu sebanyak 73 orang $(43,2 \%)$. Dari segi pendidikan terakhir, persentase terbanyak pada lulusan SMA/SMK/MA yaitu sebanyak 78 orang (46,2\%). Di lihat dari distribusi pekerjaan, sebanyak 84 orang $(49,7 \%)$ bekerja sebagai ibu rumah tangga. Sedangkan pada kejadian keputihan sebanyak 103 orang $(60,9 \%)$ tidak mengalami keputihan. Sebanyak 120 orang $(71 \%)$ melakukan praktik vaginal douching. Pada sisi frekuensi melakukan praktik vaginal douching, presentase terbanyak dilakukan secara sering oleh 65 orang $(38,5 \%)$. Bahan yang paling banyak digunakan adalah sabun mandi digunakan oleh 39 orang $(23,1 \%)$ [Tabel 1]. rendah dan sebanyak 72 orang $(42,6 \%)$ memiliki tingkat persepsi kerentanan tinggi dimana subyek peneliti takut akan mudah terkena penyakit pada vagina, dan menyebabkan rasa tidak nyaman pada vagina sehingga subyek penelitian dapat memutuskan untuk melakukan praktik tersebut. Sedangkan 84 orang $(49,7 \%)$ menunjukkan bahwa mereka memiliki tingkat persepsi manfaat rendah dan sebanyak 85 orang $(50,3 \%)$ memiliki tingkat persepsi manfaat tinggi dimana subyek peneliti meyakini banyak manfaat dari praktik vaginal douching diantaranya membersihkan vagina setelah haid, membuat vagina bersih dan kesat, mencegah keputihan dan membuat hubungan seksual menjadi puas. Sedangkan sebanyak 114 orang $(67,5 \%)$ memiliki tingkat persepsi hambatan rendah dan sebanyak 55 orang $(32,5 \%)$ memiliki tingkat persepsi 


\section{G. S. MUTDINIA ET AL.}

hambatan tinggi dimana subyek merasa bahwa vaginal douching tidak merepotkan, mudah dilakukan dan tidak memerlukan biaya karena bisa menggunakan campuran bahan apapun. Pada tabel ini sebanyak 70 orang $(41,4 \%)$ memiliki tingkat pendorong tindakan rendah dan sebanyak 99 orang (58,6\%) memiliki tingkat pendorong tindakan tinggi dimana faktor yang mempengaruhi subyek penelitian untuk melakukan praktik vaginal douching melalui media elektronik seperti TV dan internet. Subyek penelitian juga meyakini bahwa produk vaginal douching sudah teruji secara klinis. Serta 60 orang (35,5\%) menunjukkan tingkat efikasi diri rendah dan sebanyak 109 orang (64,5\%) memiliki tingkat efikasi diri tinggi dimana subyek penelitian mampu melakukan vaginal douching dengan baik dan benar [Tabel 2]. pencegahan infeksi genital, membersihkan darah haid, membersihkan sebelum melakukan hubungan suami istri, pencegahan keputihan, penurunan bau tidak sedap pada vagina serta keyakinan agama tertentu (7).

Teori Health Belief Model menggambarkan seseorang cenderung mengadopsi perilaku sehat ketika mereka yakin bahwa perilaku baru tersebut dapat menurunkan risiko terserang penyakit (8). Rasa terancam pada individu kemungkinan dapat membuat individu mengubah perilakunya, akan tetapi perubahan perilaku juga dapat dipengaruhi oleh kepercayaan individu tersebut terhadap manfaat dari tindakan dalam menurunkan ancaman suatu penyakit (9). Penelitian (10) mengatakan banyak wanita berpendapat jika douching perlu dilakukan agar kebersihan vagina terjaga. Menurut (3) praktik

Tabel 2. Frekuensi elemen teori Health Beliefe Model terhadap praktif vaginal douching pada wanita usia subur di Kelurahan Gelangan Desember 2018

\begin{tabular}{lcc}
\hline \multicolumn{1}{c}{ Kategori } & Frekuensi & Persentase (\%) \\
\hline Persepsi Keseriusan Rendah & 57 & 33,7 \\
Persepsi Keseriusan Tinggi & 112 & 66,3 \\
Total & 169 & 100 \\
Persepsi Kerentanan Rendah & 97 & 57,4 \\
Persepsi Kerentanan Tinggi & 72 & 42,6 \\
Total & 169 & 100 \\
Persepsi Manfaat Rendah & 84 & 49,7 \\
Persepsi Manfaat Tinggi & 85 & 50,3 \\
Total & 169 & 100 \\
Persepsi Hambatan Rendah & 114 & 67,5 \\
Persepsi Hambatan Tinggi & 55 & 32,5 \\
Total & 169 & 100 \\
Pendorong Tindakan Rendah & 70 & 41,4 \\
Pendorong Tindakan Tinggi & 99 & 58,6 \\
Total & 169 & 100 \\
Efikasi Diri Rendah & 60 & 35,5 \\
Efikasi Diri Tinggi & 109 & 64,5 \\
Total & 169 & 100 \\
\hline
\end{tabular}

Persepsi keseriusan $(\mathrm{p}=0,809)$, persepsi kerentanan $(\mathrm{p}=0,272)$, pendorong tindakan $(\mathrm{p}=0,420)$, dan efikasi diri $(\mathrm{p}=0,228)$ tidak berhubungan dengan praktik vaginal douching pada wanita usia subur di Kelurahan Gelangan secara signifikan $(\alpha<0,05)$ sehingga H0 diterima dan H1 ditolak. Dari tabel tersebut menunjukkan bahwa persepsi manfaat $(\mathrm{p}=0,008)$ dan persepsi hambatan $(p=0,001)$ berhubungan secara signifikan dengan praktik vaginal douching pada wanita usia subur di Kelurahan Gelangan secara signifikan $(\alpha<0,05)$ sehingga H0 ditolak dan $\mathrm{H} 1$ diterima [Tabel 3].

\section{PEMBAHASAN}

Persepsi manfaat berhubungan dengan praktik vaginal douching pada wanita usia subur di Kelurahan Gelangan secara signifikan dan menunjukkan nilai koefisien positif dimana ketika subyek merasakan manfaat yang baik maka praktik vaginal douching akan meningkat. Hal ini sejalan dengan penelitian (7) bahwa praktik vaginal douching dilakukan karena banyak manfaatnya seperti untuk kebersihan vagina, vaginal douching justru memberikan efek merugikan untuk flora baik pada vagina. Bilas vagina mengakibatkan terjadinya perubahan keseimbangan kimiawi dan flora vagina, sehingga wanita mempunyai faktor resiko terhadap infeksi bakteri.

Selain itu douching juga bisa menyebarkan infeksi vaginal atau servikal yang sudah menyebar ke arah atas menuju organ-organ panggul (uterus, tuba fallopi, dan ovarium). Hasil dari suatu penelitian menunjukkan bahwa perempuan yang melakukan douching vaginal secara rutin cenderung mengalami iritasi vagina. Sebagian dari subyek penelitian merasa bahwa praktik vaginal douching bermanfaat untuk menjaga organ kewanitaan (3). Dari analisa data didapatkan bahwa persepsi manfaat yang tinggi 3,547 kali lebih berisiko mempengaruhi seseorang untuk melakukan praktik vaginal douching.

Manfaat yang diyakini oleh subyek penelitian adalah bahwa praktik vaginal douching dapat mencegah infeksi menular seksual, membersihkan vagina dari sisa haid, membuat vagina wangi dan kesat, mencegah keputihan dan membuat hubungan 
suami istri menjadi lebih puas. Persepsi pemahaman yang salah dan persepsi yang rendah akan risiko kesehatan tetang vaginal douching mempengaruhi seseorang melakukan praktik tersebut.

Persepsi hambatan berhubungan dengan praktik vaginal douching pada wanita usia subur di Kelurahan Gelangan secara signifikan dan menunjukkan nilai koefisien negatif dimana ketika subyek merasakan hambatan/ kesulitan yang rendah untuk melakukan praktik vaginal douching maka praktik vaginal douching akan dilakukan. Apabila hambatan untuk melakukan praktik vaginal douching tinggi, maka praktik tersebut akan lebih sulit untuk dilakukan. berguna namun mahal, mempunyai efek samping, tidak menyenangkan, atau memakan waktu. Penelitian (11) menyatakan bahwa subyek peneliti tidak melakukan praktik vaginal douching dengan alasan menganggap bahwa vaginal douching tidak selalu memberikan efek segar dan bersih, memberikan efek yang buruk pada organ kewanitaan, tidak di anjurkan oleh agama, dan tidak mengurangi resiko infeksi (11).

Dari analisa data didapatkan hasil sebagian besar subyek mempunyai persepsi hambatan rendah dalam praktik vaginal douching. Subyek penelitian mengatakan tidak ada hambatan untuk melakukan

Tabel 3. Hasil uji hipotesis hubungan antara teori health belief model dengan praktik vaginal douching pada wanita usia subur di Kelurahan Gelangan Desember 2018.

\begin{tabular}{|c|c|c|c|c|c|c|c|c|c|}
\hline \multirow{3}{*}{ No } & \multirow{3}{*}{ Variabel } & \multicolumn{4}{|c|}{ Praktik vaginal douching } & \multirow{2}{*}{\multicolumn{2}{|c|}{ Total }} & \multirow{3}{*}{ Sig. } & \multirow{3}{*}{ Keterangan } \\
\hline & & \multicolumn{2}{|c|}{ Ya } & \multicolumn{2}{|c|}{ Tidak } & & & & \\
\hline & & f & $\%$ & f & $\%$ & \multirow[t]{2}{*}{ f } & \multirow[t]{2}{*}{$\%$} & & \\
\hline 1. & Persepsi Keseriusan & & & & & & & & \\
\hline & Tinggi & 91 & 53,8 & 21 & 12,4 & 112 & 66,2 & & \\
\hline & Rendah & 29 & 17,2 & 28 & 16,6 & 57 & 33,8 & 0,809 & Tidak Signifikan \\
\hline & Total & 120 & 71 & 49 & 29 & 169 & 100 & & \\
\hline \multirow[t]{4}{*}{2.} & Persepsi Kerentanan & & & & & & & \multirow{4}{*}{0.272} & \multirow{4}{*}{ Tidak Signifikan } \\
\hline & Tinggi & 57 & 33,7 & 15 & 8.9 & 72 & 42,6 & & \\
\hline & Rendah & 63 & 37,3 & 34 & 20,1 & 97 & 57,4 & & \\
\hline & Total & 120 & 71 & 49 & 29 & 169 & 100 & & \\
\hline \multirow[t]{4}{*}{3.} & Persepsi Manfaat & & & & & & & \multirow{4}{*}{0,008} & \multirow{4}{*}{ Signifikan } \\
\hline & Tinggi & 73 & 43,2 & 12 & 7,1 & 85 & 50,3 & & \\
\hline & Rendah & 47 & 27,8 & 37 & 21,9 & 84 & 49,7 & & \\
\hline & Total & 120 & 71 & 49 & 29 & 169 & 100 & & \\
\hline \multirow[t]{4}{*}{4.} & Persepsi Hambatan & & & & & & & & \\
\hline & Tinggi & 27 & 16 & 28 & 16,6 & 55 & 32,5 & \multirow{3}{*}{0,001} & \multirow{3}{*}{ Signifikan } \\
\hline & Rendah & 93 & 55 & 21 & 12,4 & 114 & 67,5 & & \\
\hline & Total & 120 & 71 & 49 & 29 & 169 & 100 & & \\
\hline \multirow[t]{4}{*}{5.} & Pendorong Tindakan & & & & & & & \multirow{4}{*}{0,420} & \multirow{4}{*}{ Tidak Signifikan } \\
\hline & Tinggi & 84 & 50 & 25 & 14,8 & 109 & 64,5 & & \\
\hline & Rendah & 36 & 21 & 24 & 14,2 & 60 & 35,5 & & \\
\hline & Total & 120 & 71 & 49 & 29 & 169 & 100 & & \\
\hline \multirow[t]{4}{*}{6.} & Efikasi Diri & & & & & & & \multirow{4}{*}{0,228} & \multirow{4}{*}{ Tidak Signifikan } \\
\hline & Tinggi & 77 & 45,6 & 22 & 13 & 99 & 58,6 & & \\
\hline & Rendah & 43 & 25,4 & 27 & 16 & 70 & 41,4 & & \\
\hline & Total & 120 & 71 & 49 & 29 & 169 & 100 & & \\
\hline
\end{tabular}

Hasil penelitian ini sesuai dengan teori Health Belief Model dimana dalam melakukan tindakan pencegahan suatu penyakit maupun mencari pengobatan dipengaruhi oleh perceived barier yaitu hambatan yang timbul dalam melakukan suatu tindakan.

Hambatan umum yang dialami seseorang dalam menentukan tindakan kesehatan atau memanfaatkan pelayanan kesehatan didominasi oleh kendala yang bersifat pribadi. Hambatan yang dirasakan merupakan unsur penentu terjadi perubahan perilaku atau tidak (9). Menurut (9) persepsi hambatan merupakan aspek negatif dari suatu perilaku sehat, dapat berupa tindakan yang menghalangi untuk berperilaku sehat, semacam bawah sadar, analisis biaya-manfaat, dimana seseorang mempertimbangkan manfaat yang diharapkan dari suatu tindakan dengan barrier (halangan) yang dirasakan. Misalnya, tindakan ini praktik vaginal douching karena praktik tersebut mudah dilakukan dan tidak merepotkan. Hal ini menunjukkan bahwa hambatan yang rendah akan meningkatkan praktik vaginal douching sebesar 0,235 kali. Persepsi hambatan yang tidak dirasakan oleh subyek penelitian merupakan persepsi yang buruk.

Persepsi keseriusan tidak berhubungan dengan praktik vaginal douching pada wanita usia subur di Kelurahan Gelangan secara signifikan. Keyakinan responden akan pentingnya melakukan praktik vaginal douching tidak mempengaruhi praktik tersebut. Teori Health Belief Model menggambarkan persepsi keseriusan terhadap keparahan suatu penyakit yang jika tidak diobati dapat menyebabkan kematian. Agar seseorang bertindak untuk mengobati atau mencegah penyakitnya ia harus merasakan bahwa ia rentan (susceptibility) terhadap penyakit tersebut. 


\section{G. S. MUTDINIA ET AL.}

Hal ini mengacu sejauh mana seorang berpikir penyakit atau kesakitan tersebut merupakan ancaman kepada dirinya. Asumsinya adalah bahwa bila ancaman yang dirasakan tersebut meningkat maka perilaku pencegahan juga akan meningkat. Perilaku tentang ancaman yang dirasakan ini terbentuk karena adanya persespi keseriusan dan kerentanan yang dirasakan (12). (13) mengatakan praktik douching berhubungan dengan rendahnya status ekonomi seseorang dan perbedaan umur seseorang. Hubungan antara douching dengan status sosial ekonomi yang rendah terlihat dari pencapaikan edukasi dan pendapat seseorang. Begitu juga dengan perbedaan umur antar pasangan, dimana ketika ada pasangan laki-laki berumur 4 tahun lebih tua/lebih) maka dari mereka lebih empati terhadap kebersihan vagina. Sehingga tidak jarang dari mereka menyarankan pasangannya untuk menjaga kebersihan vagina dengan douching (13).

Dari analisa data diatas terdapat faktor lain yang menyebabkan persepsi keseriusan tidak mempengaruhi praktik vaginal douching pada wanita usia subur di Kelurahan Gelangan. Hal ini dipengaruhi oleh pengetahuan dan pengalaman orang dalam praktik vaginal douching. Sebagian besar subyek memiliki pendidikan terakhir SMA/SMK/MA dimana jarangan terpapar oleh pendidikan kesehatan reproduksi wanita tentang kebersihan vagina sehingga pengalaman tentang vaginal douching tidak ada. Pengalaman praktik vaginal douching yang kurang memungkinkan seseorang untuk tidak melakukan hal baru tersebut sehingga tidak ada faktor dorongan yang mempengaruhinya.

Tetapi sebagaian subyek penelitian ada juga yang berpendidikan terakhir perguruan tinggi dimana sudah mahir terhadap penggunaan media elektronik informasi dari internet sudah banyak sehingga informasi yang benar tentang praktik vaginal douching. Sebagian besar subyekpun tidak mengalami keputihan. Subyek mengatakan pengalaman keputihan dianggap sebagai hal yang wajar karena cara vagina dalam melindungi bakteri yang masuk, tetapi mereka percaya jika vaginal douching mempunyai manfaat yang lain untuk vagina. Sebagian subyek penelitian yang tidak melakukan praktik vaginal douching mengatakan memiliki keyakinann bahwa praktik vaginal douching penting dilakukan guna menjaga kesehatan reproduksi wanita agar terhindar dari penyakit vagina.

Persepsi kerentanan tidak berhubungan dengan praktik vaginal douching pada wanita usia subur di Kelurahan Gelangan secara signifikan. Subyek dengan persepsi kerentanan rendah berisiko melakukan praktik vaginal douching, tetapi sebagian subyek dengan persepsi kerentanan tinggi juga berisiko melakukan praktik tersebut. Dapat diartikan bahwa persepsi kerentanan yang tinggi maupun rendah terhadap praktik vaginal douching tidak mempengaruhi praktik vaginal douching. Hal ini tidak sejalan dengan penelitian (6) bahwa ada hubungan antara persepsi kerentanan terhadap IMS pada praktik vaginal douching dengan $\mathrm{p}$ value = 0,035 .

Perbedaan karakteristik yang mencolok karena subyek pada penelitian tersebut adalah pekerjaan subyek yang berkerja sebagai wps sehingga memerlukan praktik vaginal douching untuk mencegah IMS. Teori Health Belief Model menggambarkan persepsi kerentanan sebagai keyakinan akan keseriusan atau keparahan individu terhadap suatu penyakit sehingga seseorang melakukan tindakan pengobatan atau pencegahan penyakit tersebut. Makin berat resiko penyakit, maka makin besar kemungkinan individu merasa terancam. Ancaman ini mendorong tindakan individu untuk melakukan tindakan pencegahan atau penyembuhan penyakit. Menurut (14) setiap individu mempunyai cara tersendiri dalam memutuskan tindakan kesehatan yang ditujukan untuk mengatasi gangguan kesehatan yang ada.

Semua keputusan tergantung dari keyakinan masing-masing individu dimana keyakinan yang dimaksud berkaitan dengan kognitif seperti pengetahuan tentang masalah kesehatan dan persepsi individu mengenai gejala penyakit yang dirasakan (14). Penelitian (15) menyatakan bahwa wanita memiliki persepsi yang salah tentang praktik vaginal douching. Mereka merasa bau dan keputihan yang dirasakan adalah kejadian yang tidak normal sehingga menyiratkan bahwa keputihan tidak dilihat sebagai bagian dari kesehatan vagina (15).

Dari analisis data diatas terdapat faktor lain yang menyebabkan persepsi kerentanan tidak mempengaruhi praktik vaginal douching pada wanita usia subur di Kelurahan Gelangan. Sama seperti halnya dengan persepsi keseriusan, faktor lain dapat dipengaruhi oleh pengetahuan dan pengalaman orang dalam praktik vaginal douching. Pengetahuan seseorang dipengaruhi oleh tingkat pendidikan yang mana sebagian besar subyek penelitian memiliki pendidikan terakhir SMA/SMK/MA. Pengalaman diri sendiri maupun orang sekitar tentang praktik vaginal douching akan mempengaruhi keyakinan seseorang dalam membangun persepsi/ keyakinannya. Sebagian besar subjek banyak yang berprofesi di kantor sehingga memungkinnya adanya paparan informasi yang lebih luas terkait praktik vaginal douching.

Pendorong tindakan tidak berhubungan dengan praktik vaginal douching dimana sebanyak 58,6\% merasakan faktor pendorong tindakan tinggi sedangkan sebanyak 41,4\% merasakan faktor pendorong tindakan yang rendah. Berdasarkan analisis seberapapun faktor pencetus yang diterima, dimana pendorong tindakan subjek tinggi maupun rendah tidak akan mempengaruhi praktik responden melakukan praktik vaginal douching yang tetap tinggi. Hal ini sejalan dengan penelitian (16) bahwa tidak ada hubungan antara isyarat bertindak dengan praktik vaginal douching yang berisiko IMS dengan $\mathrm{p}$ value $=0,151$. Teori Health Belief Model bahwa dalam melakukan tindakan kesehatan terdapat faktor 
pencetus untuk memutuskan, menerima atau menolak alternatif tindakan tersebut.

Isyarat ini dapat bersifat internal maupun eksternal. Isyarat internal yaitu berasal dari dalam diri individu. Sedangkan isyarat eksternal yaitu berasal dari interaksi intersosial, misalnya media massa, pesan, nasihat, anjuran atau konsultasi dengan petugas kesehatan (6). Determinan lingkungan mempengaruhi perilaku kesehatan seseorang termasuk semua aspek fisik individu yang mengelilinginya diantaranya aspek informasi baik elektronik maupun cetak serta jarak dengan pelayanan dan pendidikan kesehatan. Penelitian (11) mengatakan dorongan utama untuk melakukan vaginal douching dapat berasal dari orang terdekat seperti ibu, diri sendiri, kerabat dekat dan pasangan sehingga seseorang tersebut dapat tertarik untuk melakukan praktik tersebut (11). Penelitian (4) mengatakan wanita terdorong untuk melakukan vaginal douching karena iklan yang di promosikan oleh produk tersebut.

Produk tersebuk dijual secara bebas komersil dengan sugesti-sugesti bahwa produk tersebut dapat membuat organ kewanitaan menjadi bersih segar dan tidak bau sehingga wanita tertarik mencobanya (4). Dari hasil analisis yang didapatkan faktor pendorong tindakan tidak berhubungan dengan praktik vaginal douching karena sebagian subyek peneliti mengatakan bahwa dari faktor eksternal memang banyak sumber-sumber infomasi yang didapatkan seperti dari iklan di TV, majalah, koran maupun internet tetapi sebagian orang mengatakan bahwa belum tentu praktik vaginal douching sudah di uji dengan baik kebenarannya untuk menjaga organ kesehatan wanita. Mudah didapatkannya bahanbahan untuk praktik vaginal douching seperti sbaun mandi, rebusan daun sirih dan cairan pembersih vagina tidak mempengaruhi subyek untuk melakukan praktik tersebut.

Faktor internal seperti kondisi yang mendukung subyek untuk melakukan praktik vaginal douching seperti tidak adanya masalah pada organ kewanitaan yang dirasakan serta tidak adanya dorongan dari orang sekitar membuat subyek tidak melakukan tindakan tersebut. Tinggi rendahnya informasi/ dorongan yang didapatkan subyek dalam melakukan tidak mempengaruhi subyek melakukan praktik tersebut. Ketika kebiasaan praktik vaginal douching dilakukan dan menimbulkan manfaat yang baik makan subjek akan melakukanya ketika sudah meyakininya.

Efikasi diri tidak berbuhungan dengan praktik vaginal douching. Teori Health Belief Model menggambarkan efikasi diri sebagai keyakinan individu terhadap kemampuannya untuk melakukan suatu tindakan dimana individu memang mampu. Jika individu yakin bahwa perilaku itu berguna tetapi tidak yakin mampu melakukannya maka ia akan melakukan hal baru. Beberapa literatur menyebutkan bahwa self-efficacy merupakan pendukung dalam menginisiasi dan memelihara perubahan perilaku (9).
Seseorang harus merasa dirinya kompeten dalam melakukan perilaku yang baru sehingga dapat mengatasi hambatan yang menghalangi adopsi perilaku baru. Menurut Bandura dalam (17) mengatakan bahwa efikasi diri terbentuk melalui 3 proses yaitu, proses kognitif, proses motivasi, proses afeksi dan proses seleksi (17). Penelitian (10) mengatakan bahwa motivasi wanita untuk melakukan praktik vaginal douching karena banyak manfaatnya seperti membersihkan vagina setelah haid, mengurangi bau tidak sedap dan sebagaian. Faktor lain yang mempengaruhi wanita termotivasi untuk melakukan praktik tersebut adalah budaya yang diturunkan oleh ibu, teman dan keputusan sendiri untuk melakukan douching (10).

Hasil analisis data tidak ada hubungan yang signifikan diakibatkan proses motivasi yang tidak mendukung. Tingi atau rendahnya efikasi diri subyek tidak mempengaruhi untuk melakukan praktik vaginal douching. Sebagain subyek penelitan yang mampu melakukan vaginal douching dengan benar tidak melakukan praktik tersebut. Hal ini dapat terjadi karena sebagian masyarakat bekerja di perkantoran (di luar ibu rumah tangga) sehingga memungkinkan paparan informasi dari kantor maupun kerabat dekat melalui media elektronik tinggi, sehingga informasi tentang praktik vaginal douching yang aman di dapatkan. Hal ini juga didasari oleh keadaan tidak mendukung seperti tidak adanya kondisi yang mengharuskan subyek untuk melakukan praktik vaginal douching, serta tidak adanya dorongan dari orang terdekat untuk melakukan praktik vaginal douching.

\section{KESIMPULAN}

Persepsi keseriusan tentang pentingnya praktik vaginal douching untuk dilakukan, tidak meningkatkan praktik vaginal douching pada wanita usia subur di Kelurahan Gelangan. Begitu juga dengan persepsi kerentanan bahwa praktik vaginal douching dapat mencegah penyakit organ kewanitaan tidak meningkatkan praktik vaginal douching pada wanita usia subur di Kelurahan Gelangan. Persepsi manfaat praktik vaginal douching meningkatkan tindakan praktik vaginal douching pada wanita usia subur di Kelurahan Gelangan.

Ketika persepsi manfaat yang dirasakan meningkat maka keputusan untuk melakukan praktik vaginal douching juga meningkat. Selain itu, jika persepsi hambatan yang dirasakan klien untuk melakukan praktik tersebut tergolong rendah, maka hal ini meningkatkan tindakan praktik vaginal douching. Faktor pendorong tindakan seperti banyaknya iklan tentang vaginal douching melalui media sosial dan elektronik tidak membuat wanita usia subur di Kelurahan Gelangan melakukan praktik tersebut. Kemampuan untuk melakukan vaginal douching dengan benar oleh wanita usia subur di Kelurahan Gelangan tidak mempengaruhi subyek untuk melakukan praktik tersebut. 


\section{UCAPAN TERIMA KASIH}

Kami mengucapkan terima kasih kepada Kesbangpol Kota Magelang serta Pemerintahann Daerah Kelurahan Gelangan Kecamata Magelang Tengah Kota Magelang untuk izin dan penerimaan kami untuk mengambil data sebagai bahan penelitian dan semua perawat yang telah bersedia menjadi responden.

\section{DAFTAR PUSTAKA}

1. Nurhudhariani R, Hardiyaningsih L. Fenomena Vagina Practice Terhadap Kesehatan Reproduksi Wanita Usia Subur Di Purwodadi. Semin Nas Kesehat Reproduksi Menuju Gener Emas. 2017;1(1):101-7.

2. Marlena R. Hubungan Vaginal Douching Dengan Kejadiankeputihan Pada Wanita Usia Muda. 2016;

3. Aslan E, Bechelaghem N. To 'douche ' or not to ' douche ': hygiene habits may have detrimental effects on vaginal microbiota. J Obstet Gynaecol (Lahore). 2018;0(0):1-4.

4. Cottrell BH. An Updated Review of of Evidence to Discourage Douching. MCN, Am J Matern Nurs. 2010 Mar;35(2):102-7.

5. Supriyatiningsih S. Monograf Penggunaan Vaginal Douching Terhadap Kejadian Candidiasis Pada Kasus Leukorea. 2015;

6. Widyasari DN. Faktor-Faktor Yang Berhubungan Dengan Praktik Vaginal Douching Yang Berisiko Menularkan Ims Pada Wps Di Resosialisasi Argorejo Semarang. Universitas Negeri Semarang; 2016.

7. Yanikkerem E, Yasayan A. Vaginal douching practice: Frequency, associated factors and relationship with vulvovaginal symptoms. J Pak Med Assoc. 2016;66(4):387-92.
8. Hayden J. Introduction to Health Behavior Theory. Massachusetts: Jones and Bartlett Publishers; 2009.

9. Glanz K, Rimer BK, Viswanath K (Kasisomayajula), Orleans CT. Health behavior and health education: theory, research, and practice. Jossey-Bass; 2008. p. 552.

10. Caliskan D, Subasi N, Sarisen O. Vaginal douching and associated factors among married women attending a family planning clinic or a gynecology clinic. Eur J Obstet Gynecol Reprod Biol. 2006 Aug;127(2):244-51.

11. Kukulu K. Vaginal douching practices and beliefs in Turkey. Cult Health Sex. 2006 Jul;8(4):371-8.

12. Notoatmodjo S. Metodologi penelitian Kesehatan. Jakarta: Rineka Cipta; 2010.

13. DiClemente RJ, Young AM, Painter JL, Wingood GM, Rose E, Sales JM. Prevalence and Correlates of Recent Vaginal Douching among African American Adolescent Females. J Pediatr Adolesc Gynecol. 2012 Feb;25(1):48-53.

14. Sarafino EP. Health Psychology; Biopsychosocial interactions. 2006.

15. Jenkins AL, Crann SE, Money DM, O’Doherty KC. “Clean and Fresh": Understanding Women's use of Vaginal Hygiene Products. Sex Roles. 2018 May;78(9-10):697-709.

16. Chussurur, Mifta Hidayat, Thulus Agustin RW. Pengaruh pemberian cerita melalui media audiovisual terhadap. Universitas Sebelas Maret Surakarta; 2011.

17. Hendiarto $Y$, Hamidah. Hubungan antara SelfEfficacy dengan Perilaku Sehat pada Penderita Jantung Koroner. Vol. 03, Jurnal Psikologi Klinis dan Kesehatan Mental. 2014. 